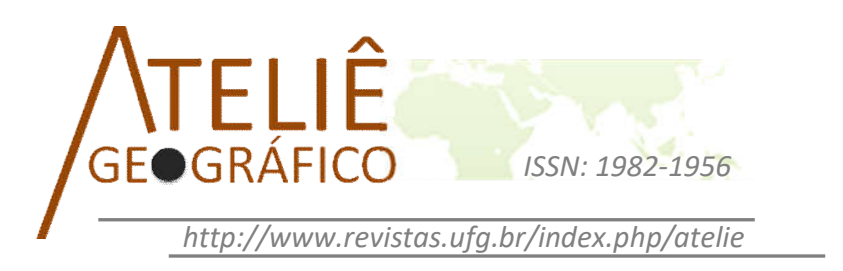

\title{
Perspectivas e possibilidades do ensino interdisciplinar nas escolas do campo
}

\author{
Perspectivas y posibilidades de la enseñanza interdisciplinar \\ en las escuelas del campo
}
Perspectives and possibilities of interdisciplinary teaching in country schools

José Novais de Jesus

Universidade Federal de Goiás

novaisdejesus@yahoo.com.br

Edevaldo Aparecido Souza

Universidade Estadual de Goiás

ediueg@gmail.com

\begin{abstract}
Resumo
A Educação é uma atividade importante para a formação da sociedade, urbana e rural, no entanto, há muito têm se estabelecido condições subalternas ao campo no que diz respeito a atividades tradicionais e, nessa linha de pensamento, a educação nas escolas rurais deu-se, por muitas décadas, a partir de parâmetros urbanos. Na Educação formal, para o espaço rural, há uma naturalização dos impactos ambientais e das desigualdades sociais, cujo objetivo denota a naturalização da desconstrução do saber tradicional e das práticas socioeducativas camponesas. Por conta dessas estratégias ideologizantes, os movimentos sociais do campo constroem propostas pedagógicas estabelecendo os camponeses como protagonistas do ensino/aprendizagem a partir da proposta da Educação do Campo, que se alicerça em pedagogias libertadoras como a da alternância. Também é necessário que a proposta pedagógica seja interdisciplinar, no sentido de que todas as disciplinas trabalhem os seus conteúdos específicos a partir da realidade dos protagonistas. Assim, os alunos constroem o saber a partir das suas experiências.
\end{abstract}

Palavras-chave: Educação do Campo. Ensino Interdisciplinar. Camponeses.

\begin{abstract}
Education is an important activity for making a society, urban and rural. However, there have been subaltern conditions in the country regarding traditional activities. Following this line of reasoning, education in rural schools have been performed from an urban standpoint for several decades. Concerning rural space formal education, one might see a naturalization of environmental impacts and social
\end{abstract}


inequalitity, whose goal is to indicate the naturalization of the deconstruction of traditional knowledge and peasant-related social educational practices. Due to such ideologizing strategies, social movements in the country develop pedagogical proposals establishing peasants as protagonists of teaching and learning based on the Education in the Country proposal, which stems to freeing pedagogies such as the Alternance Pedagogy. It is also necessary to promote an interdisciplinary pedagogical proposal, aiming at pooling disciplines so as to deal with specific content having protagonists' reality as a starting point. Thus, students build their knowledge from their experience.

Keywords: Education; Country; Interdisciplinary Teaching; Peasants.

\begin{abstract}
Resumen
La Educación es una actividad importante para la formación de la sociedad, urbana y rural, sin embargo hace mucho se han establecido condiciones subalternas al campo a respeto a atividades tradicionales y, así, la educación en las escuelas rurales ocurre, por muchas décadas, a partir de parámetros urbanos. En la Educación formal, para el espacio rural, hay una naturalización de los impactos ambientales y de las desigualdades sociales cuyo objetivo denota la naturalización de la desconstrucción del saber tradicional y de las prácticas socioeducativas campesinas. A causa de esas estrategias ideologizantes, los movimientos sociales del campo construyen propuestas pedagógicas estableciendo los campesinos como protagonistas de la enseñanza/aprendizaje a partir de la propuesta de la Educación del Campo, que se basa en pedagogías libertadoras como la da alternancia. También es necesario que la propuesta pedagógica sea interdisciplinar, para que todas las disciplinas trabajen sus contenidos específicos a partir de la realidad de los protagonistas. Así, los alumnos construyen el saber a partir de sus experiencias.
\end{abstract}

Palabras clave: Educación; Campo; Enseñanza Interdisciplinar; Campesinos

\title{
Introdução
}

Sabe-se que a Educação é um dos instrumentos mais importantes para a construção da sociedade. No entanto, há diversos modelos para se estruturarem as bases da construção do saber, que perpassam instituições diversas e antagônicas - a partir das as quais abordaremos a Educação Formal.

No processo de formação, a partir da Educação Formal e das estratégias marketeiras apresentadas nos meios de comunicação social, há uma naturalização das desigualdades sociais cujo objetivo, dentre outros, reside na desconstrução do saber tradicional e das práticas socioeducativas camponesas (que se iniciam na infância e perpassam várias fases da vida dos sujeitos que ainda permanecem no campo, assim como na dos trabalhadores da cidade).

Há uma estratégia do capital, nessa construção do saber hegemônico, de se fazer acreditar que a moderna agricultura é socialmente justa, ambientalmente correta e que permite o desenvolvimento social de qualquer pessoa que, de fato, tenha interesse em trabalhar. $\mathrm{Na}$ verdade, esse pensamento concretiza-se em ações que produzem contradições e desumanidades em todos os lugares em que seus tentáculos se assentam. 
Desse modo, as transformações no campo pelo processo de modernização do território, a partir da modernização agrícola/tecnológica, alteraram profundamente as formas produtivas tradicionais e também promoveram profundas metamorfoses nas relações socioculturais e ambientais nos territórios camponeses.

Diante disso, parte da sociedade, sobretudo os movimentos sociais do campo, vêm construindo propostas pedagógicas por meio de processos educacionais libertadores, como a Educação do Campo, cujos protagonistas são os camponeses. De acordo com Caldart (2004), o desafio teórico atual é o de construir o paradigma (contrahegemônico) da Educação do Campo, ou seja, construir teorias, concepções, conceitos e ideias de interpretação da realidade e assumir uma tomada de posição para a construção do saber local.

Isso quer dizer que é preciso pensar a Educação dos camponeses e dos seus filhos numa perspectiva político-pedagógica que atenda aos interesses sociais, econômicos, políticos, culturais e ambientais desse grupo social - gestado sob o ponto de vista desses sujeitos e para as suas necessidades e interesses, a fim de realizar as perspectivas estabelecidas em suas trajetórias de luta e organização, que precisam ser repensadas já nas fases iniciais da educação.

Também é necessário que a proposta pedagógica seja interdisciplinar, no sentido de que todas as disciplinas trabalhem os seus conteúdos específicos a partir da realidade dos protagonistas, ou seja, os alunos e seus familiares; os alunos e suas experiências; os alunos e suas relações com as atividades do campo e com o meio ambiente; os alunos e suas formas de linguagem; os alunos e seus modos de vida.

O ensino das escolas do campo também deve atentar para as questões metodológicas e didáticas para possibilitar aos alunos uma compreensão a partir da sua realidade. Por isso, os professores precisam conhecer a problemática do espaço rural. As práticas pedagógicas, nesse sentido, teriam que estar voltadas para atender uma especificidade de pensar o campo numa perspectiva particular e, no aspecto geral, para compreender os desafios e as perspectivas das escolas do campo.

\section{Os desafios do ensino nas escolas no campo}

Sem dúvida, o campo passou por profundas transformações socioespaciais nas últimas décadas, mudanças que trouxeram como consequência o aumento da migração campo-cidade. A expansão das inovações tecnológicas no espaço rural impôs para os povos do campo um padrão dito moderno e, em contrapartida, a substituição das suas práticas culturais.

No que se refere ao ensino nas escolas rurais brasileiras, tem-se uma situação preocupante, pois o índice de analfabetismo ainda é alto em relação a escolas urbanas. Segundo Peres (2011, p. 638):

Não sem motivo, é no meio rural que encontramos os mais baixos índices de escolaridade de toda a sociedade brasileira. Os dados do INEP, sistematizados no trabalho intitulado Panorama da Educação 
do Campo (2007), mostram que a escolaridade média da população de 15 anos ou mais, que vive no meio rural brasileiro, que é de 3,4 anos, corresponde à quase metade da estimada para a população urbana, que é de 7,0 anos. Se os índices de analfabetismo no Brasil são bastante elevados, no meio rural esses indicadores são ainda mais preocupantes.

Os dados ilustram o descaso das políticas públicas educacionais para as populações do espaço rural e demonstram a necessidade de se criarem condições para melhorar a qualidade das escolas no campo e reduzir os índices de analfabetismo, muito desproporcional aos índices do meio urbano. Desse modo, há que se repensar o campo a partir da sua complexidade para que sejam entendidos os principais dilemas e possibilidades que requerem as escolas no campo.

O desafio para o poder público é apresentar soluções concretas para garantir aos alunos do campo as mesmas condições de oportunidades e igualdades proporcionadas aos alunos das escolas do espaço urbano. Outrossim, faz-se necessário melhorar a qualidade do ensino, aplicar procedimentos didático-pedagógicos que melhorem o nível de aprendizagem dos alunos das escolas rurais. Os dados apresentados nos revelam o descaso do poder público em relação as escolas do campo. Os camponeses também têm direito ao ensino de qualidade e gratuito para todos, como reza a Constituição Federal de 1988. Vale ressaltar o direito de ter a escola no campo para não precisar deixar o campo para estudar.

Um dos grandes desafios das escolas rurais é que a prática de ensino ainda é descontextualizada da realidade camponesa - pois não costuma ser discutida a problemática do cotidiano dos alunos, ou seja, o campo é visto apenas como espaço de localização geográfica. Essa leitura precisa ser feita para, então, conceber um projeto de educação que possa possibilitar uma compreensão do campo de modo a não dissociá-lo da cidade - visto que há uma relação recíproca entre o rural e o urbano. Por isso, pensar a escola do campo nessa perspectiva também requer a construção de pressupostos teórico-metodológicos para viabilizar tal ensino.

Nesse contexto, a educação rural no Brasil surge sem preocupação de contribuir com a formação da cidadania, haja vista que as elites da época argumentavam que "gente da roça não precisa de escola". Uma lógica segundo a qual a escola era para pessoas da cidade. Segundo Arroyo, Caldart e Molina (2004, p. 10):

As políticas educacionais no Brasil padecem de uma indefinição de resumos. E as políticas para o campo ainda mais. A escola no meio rural passou a ser tratada como resíduo do sistema educacional brasileiro e, consequentemente, à população do campo foi negado o acesso aos avanços havidos nas duas últimas décadas no reconhecimento e garantia do direito à educação básica. $\mathrm{O}$ que aconteceu para que nem sequer o movimento pedagógico progressista e o movimento docente tão politizado e as políticas sociais mais inclusivas tenham chegado a incluir o povo do campo como sujeito de direitos? 
A carência de políticas públicas educacionais para o campo faz parte do processo histórico da educação brasileira, quando os camponeses tinham negados os direitos de frequentar escola. Isso implica dizer que as escolas do campo são as mais prejudicadas em função do descaso e da ausência de uma atenção especial capaz de melhorar a qualidade do ensino e, ao mesmo tempo, garantir aos camponeses o acesso à educação.

Nessa perspectiva, é importante rever o modelo de educação para se pensar na construção de um novo projeto de educação para os povos do campo. A discussão dessas questões necessita da participação dos trabalhadores rurais, dos movimentos sociais de luta pela terra, de instituições de ensino e de universidades que possam contribuir para debater a problemática das escolas no espaço rural. De acordo com Almeida (2013, p. 5), "a Educação do Campo é uma conquista dos movimentos sociais do campo, em específico do movimento camponês, na busca da valorização dos sujeitos do campo".

Desse modo, a educação no/do campo não pode estar desvinculada dos interesses dos camponeses. Portanto, o ensino deve contribuir para ajudar a refletir a realidade, os valores culturais, a política e o mundo. Para Caldart (2004, p. 19):

O movimento inicial da Educação do Campo foi o de uma articulação política de organizações e entidades para denúncia e luta por políticas públicas de educação no e do campo, e para mobilização popular em torno de um outro projeto de desenvolvimento. Ao mesmo tempo tem sido um movimento de reflexão pedagógica das experiências de resistência camponesa, constituindo a expressão, e aos poucos o conceito de educação do Campo.

A iniciativa da criação do conceito da Educação do Campo teve como objetivo denunciar a situação das escolas rurais e mobilizar as organizações e as entidades para reivindicar políticas públicas e refletir as questões pedagógicas a partir das lutas camponesas.

Assim, os povos do campo têm o direito à escola no campo. Conforme afirma Caldart (2004, p. 28): "trata-se de uma educação dos e não para os sujeitos do campo". Ainda nessa perspectiva, Kolling, Nery e Molina (1999, p. 23) afirmam que "um primeiro desafio que se tem é perceber qual educação está sendo oferecida ao meio rural e que concepção de educação está presente nessa oferta". Essa questão é crucial para analisar como as escolas rurais concebem os problemas socioculturais dos sujeitos do campo.

Vale salientar que a concepção da Educação do Campo trata de diferentes sujeitos, como menciona Caldart (2004, p. 153):

O campo tem diferentes sujeitos. São pequenos agricultores, quilombolas, povos indígenas, pescadores, camponeses, assentados, reassentados, ribeirinhos, povos da floresta, caipiras, lavradores, roceiros, sem-terra, agregados, caboclos, meeiros, assalariados rurais e outros grupos mais. Entre estes há os que estão ligados a alguma forma de organização popular, outros não; 
há ainda as diferentes etnias, de religião, de geração; são diferentes jeitos de produzir e de viver; diferentes modos de olhar o mundo, de conhecer a realidade e de resolver os problemas; diferentes jeitos de fazer a própria resistência no campo; diferentes lutas.

Suprir as demandas dessa diversidade existente no campo brasileiro e no território goiano requer uma escola comprometida e diferente, que se comprometa a compreender essa complexidade dos diferentes povos que residem e trabalham no espaço rural. São sujeitos que têm modos de vida diferenciados, de acordo com as potencialidades da sua região.

Sob esse aspecto, entendemos o campo como espaço de lutas, de produção, de conflitos e também de formação, como afirma Pires (2012, p. 109): "pensar a escola do campo e não reduzir a questão aos limites da escola, mas considerar os diversos espaços e forma de educação". Por isso, é importante atentar para os currículos, a fim de que sejam construídos levando-se em conta os aspectos socioculturais dos povos do campo. Nesse sentido, Santos e Almeida (2012, p. 139) defendem que:

Durante séculos, não houve a preocupação, por parte dos responsáveis pelo sistema do ensino público, com o currículo escolar do campo, principalmente nos municípios afastados dos grandes centros urbanos, onde não havia escola. Esse fato inviabiliza a possibilidade de se poder pensar uma escola do campo como um espaço de educação própria para aqueles que vivem no e do campo.

Ainda persistem nas escolas rurais currículos que não correspondem à realidade do campo, o que indica que o sistema educacional brasileiro não se preocupa com a problemática que vivem os camponeses distantes dos grandes centros urbanos. Essa realidade demonstra que essas escolas enfrentam sérios problemas de diferentes naturezas, como a educação rural descontextualizada. Contudo, em vez, de garantir que as crianças e os adolescentes possam continuar seus estudos no campo, parece existir o estímulo para que migrem para as cidades.

A falta de políticas públicas para as escolas no campo resulta em prejuízos para aqueles que ainda desejam continuar na terra. É latente a iniciativa do poder público de transportar os alunos do campo para estudar nas escolas urbanas. Nesse sentido, corrobora Jesus (2010b, p. 149), ao afirmar que o poder público municipal tem preferido disponibilizar o transporte desses alunos para a cidade em função de contenção de custo.

Quando se refere à educação no campo, podemos perceber que há grandes entraves, pois as escolas existentes no campo estão sendo abandonadas e, na sua maioria, fechadas; os alunos são transportados para estudar na cidade. [...] Essa migração diária de alunos do campo para estudar na cidade é estimulada pelas políticas municipais que priorizam o transporte em detrimento da construção de uma estrutura físico-pedagógica no campo, com argumento de que esse sistema seria mais "econômico". 
A educação deixa de ser pensada a partir do ensino/aprendizagem para ser planejada diretamente pelo fator financeiro. No entanto, para Jesus (2010a, p. 60), é necessário "definir as políticas publicas como direito para assegurar a cidadania de uma população que mora, trabalha e que quer estudar na escola no campo, sem precisar deixar o campo para estudar".

O esforço para apresentar alguns elementos que possam contribuir com a reflexão dessas questões relacionadas ao ensino nas escolas rurais traz em seu bojo alguns questionamentos que merecem ser analisados, no que tange à organização metodológica e pedagógica da escola no campo. Conforme Leite (2002), a educação não se constituía como meta a ser alcançada, mediante um projeto escolar autônomo, técnico e pedagogicamente estruturado. A educação estava relegada a segundo plano: tanto a educação urbana quanto a educação rural.

Assim, a formação do professor tem um caráter importante nesse processo. Constata-se que muitos docentes não dispõem de qualificação adequada para atuar nas escolas rurais, o que demanda uma formação específica para os professores de tais escolas.

São muitos os problemas que afetam a educação no campo. Por esse motivo, nas últimas décadas, surgiram grandes debates em torno dessa questão, com o intuito de repensar a concepção de campo e da educação - cujo objetivo é contribuir para a criação de políticas públicas que venham ao encontro dos interesses dos povos do campo. Como afirma Pessoa (2007, p. 27), é preciso pensar uma educação vinculada e contextualizada com a realidade camponesa.

Pensar a educação rural não é, pois, pensar apenas o que fazer com as poucas escolas que geograficamente ainda continuam funcionando em regiões rurais. É pensar, sim, essa realidade, com um atendimento educacional gestado a partir dos seus anseios e necessidades. Mas há que se construir também um atendimento escolar nas outras formas de manifestação da ruralidade, mesmo que geograficamente se trate de regiões consideradas urbanas.

Pensar a educação rural é também pensar as condições em que vivem as escolas, desde a estrutura física, a disponibilidade de biblioteca, de laboratório de informática, até as áreas recreativas e de lazer. Por fim, deve-se saber qual é a verdadeira situação em que essas escolas se encontram.

Diante desse contexto, pode-se analisar que a problemática da educação no campo persiste na atualidade, apesar de termos conquistados alguns avanços no campo da formação, já que, até então, não havia professores graduados atuando nas escolas rurais. Sob esse ponto de vista, houve, sim, ganhos significativos. Já existem em vários estados do Brasil como Goiás e Mato Grosso do Sul, experiências relevantes com práticas pedagógicas diferenciadas e conectadas com as questões ligadas a realidade do campo.

No Estado de Goiás, existem três Escolas Famílias Agrícolas (EFAs) que utilizam da Pedagogia da Alternância como instrumento metodológico e pedagógico 
para fazer a educação no/do campo - a Alternância é o período alternado de vivência e estudo na Escola, na Família e na Comunidade. O princípio fundamental é não desvincular o aluno do campo, do ambiente familiar e comunitário. As EFAs estão localizadas nos municípios de Goiás, Uirapuru e Orizona.

Com o objetivo de atender os professores das escolas rurais da região e debater a Educação no/do Campo, duas propostas formam elaboradas para a Escola do Campo São Joaquim, localizada no município de Selvíria-MS. A primeira, "Paradigmas políticos, sociais e educacionais da Educação do Campo: a valorização dos saberes locais", foi uma oficina de um dia para os professores e gestores de todas as escolas do campo do Bolsão Sul-Matogrossense, em dezembro de 2015, ministrada pela Professora Dra. Mirian Lange Noal do CED/EaD/UFMS.

A segunda foi a partir do Projeto de Extensão "Formação continuada de Educação no/do Campo" para professores e gestores da Escola Municipal Rural São Joaquim, sob a coordenação da Professora Dra. Rosemeire Aparecida de Almeida, para os professores e gestores da escola São Joaquim, cujo objetivo foi a ministração de 13 oficinas ao longo de 2016, com temas abrangendo a Educação no/do campo, as concepções teórico-metodológicas, político-ideológicas e as interdisciplinaridades que compõem o currículo daquela escola.

Em junho de 2016, aconteceram outras duas oficinas, simultâneas, sobre Educação do Campo, em Paranaíba e em Chapadão do Sul, ambas em Mato Grosso do Sul, organizadas pelo Núcleo de Extensão em Desenvolvimento Territorial (NEDET). O tema em Paranaíba foi "Desafios das Escolas do Campo: princípios, planejamentos e currículo na contra-corrente", e em Chapadão do Sul "Educação do Campo e os desafios nas escolas do campo".

As oficinas objetivaram apresentar e debater sobre as práticas educativas nas áreas rurais com escolas do campo do Bolsão Sul-Matogrossense, que perpassam por instituições diversas e antagônicas de modelos de construção do saber, que reforçam (ou não) a continuidade da produção e do modo de vida camponês, pautado em valores de defesa do Cerrado e da produção agroecológica.

Em suma, o fortalecimento das políticas públicas pode, de fato, contribuir para o fortalecimento das escolas rurais, criando condições necessárias para aprimorar o ensino e possibilitar melhores oportunidades para os jovens camponeses. Outra questão relevante é fomentar a participação das famílias no que tange aos problemas que as escolas no campo estão enfrentando e estimular a comunidade a participar e decidir que escola desejam para o campo. Uma escola que contemple as necessidades atuais e que possa ajudar a encontrar alternativas para a superação dos problemas.

Para tanto, a problemática exposta referente aos desafios pelos quais passam as escolas no campo exige do poder público e das instituições de ensino (universidades), principalmente dos cursos de licenciatura, instrumentos para debater as escolas rurais juntamente com os profissionais da educação, especificamente com os professores que já lecionam no campo. O que se observa é que não existe uma preocupação com essas questões que deveriam estar presentes nas academias de ensino. A reflexão sobre a 
situação do ensino das escolas rurais torna-se cada dia mais crucial para entendermos os desafios e as possibilidades postas no campo.

\title{
O ensino das escolas do campo em uma perspectiva interdisciplinar
}

Esse processo pelo qual passa a educação no espaço rural não pode ser compreendido fora do conjunto dos problemas agrários, existentes em todas as regiões brasileiras. A modernização do campo, a migração campo-cidade, os conflitos por terra, e as políticas públicas que também contribuem para a retirada dos jovens do campo com o consequente fechamento das escolas rurais - são conteúdos interligados à Educação do Campo e que precisam dialogar também com as várias ciências que atuam na área educacional. Portanto, a interdisciplinaridade torna-se uma necessidade para as análises e debates acerca dessas questões.

A interdisciplinaridade também permite aos alunos elementos para ler e interpretar a realidade, a partir dos mais diversos aspectos: social, econômico, cultural e ambiental. É necessário que os conteúdos pedagógicos estejam vinculados à realidade dos alunos, desafiando o corpo docente a desenvolver estratégias metodológicas que levem os alunos a refletir a partir de temas ligados aos problemas reais.

Levando-se em consideração Costa, Alves e Faleiro (2015, p. 52), entendemos que na "interdisciplinaridade tem-se uma relação de reciprocidade, frisando a interdependência, a interação, a comunicação existente entre as disciplinas num sistema lógico de conhecimentos, com livre trânsito de um campo de saber para outro". Nessa perspectiva:

\begin{abstract}
A interdisciplinaridade provoca trocas generalizadas de informações e de críticas, amplia a formação geral e questiona a acomodação dos pressupostos implícitos em cada área, fortalecendo o trabalho de equipe. Em vez de disciplinas fragmentadas, a interdisciplinaridade postula a construção de interconexões apresentando-se como arma eficaz contra a pulverização do saber. (COSTA; ALVES; FALEIRO, 2015, p. 52).
\end{abstract}

Há que repensar as práticas de ensino nas escolas do campo sob a perspectiva da das ações e dos modos de vida das populações do campo, dentro das especificidades de cada grupo social: camponeses, ribeirinhos, quilombolas, indígenas, caiçaras, seringueiros, geraizeiros, pantaneiros, quebradeiras de coco babaçu, dentre outros.

Para Bertti (2007, p. 97), "pensar a educação das populações que vivem no campo implica desvelar a problemática embutida nos conflitos agrários, que colocaram em cena vários atores durante um longo processo histórico". São tensões que revelam contradições que se apresentam em função da expansão do capitalismo no campo e que trazem consequências relevantes em relação à permanência na terra e à manutenção das escolas nas áreas rurais. Essas condições vão exigir dos sujeitos do campo, professores, pais, movimentos sociais e entidades de ensino uma reflexão sobre esses acontecimentos impostos de forma perversa e contraditória nesse início de século. 
Garantir e fortalecer ao cidadão que mora no campo o direito de poder estudar em uma escola rural promove a produção do saber campesino, que se dá numa discussão dialética das lutas por terra, por educação e por melhores condições de vida no lugar que escolheu para viver.

Fernandes e Molina (2004) compreendem que é por meio da educação que surge a construção do conhecimento, necessário ao desenvolvimento das humanidades. Entretanto, "isso só é possível com uma educação voltada para os seus interesses, suas necessidades, suas identidades, aspectos não considerados pelo paradigma da educação planejada pelo capital".

Os autores (2004, p. 64) atestam que "a Educação do Campo pensa o campo e sua gente, seu modo de vida, de organização do trabalho e do espaço geográfico, de sua organização política e de suas identidades culturais, suas festas e seus conflitos".

Na perspectiva do conceito de modo de vida, a partir da memória e do gênero de vida das populações tradicionais podem ser extraídos e lapidados os elementos que permitem compreender com profundidade os sentimentos e as ações dos camponeses, bem como os elementos materiais e imateriais que aparecem relacionados nas suas práticas socioculturais, porquanto expressam representações sociais que revelam trajetórias culturais e sociais importantes para os sujeitos que os utilizam.

Os modos de vida camponeses são compostos por hábitos, costumes, habilidades, conhecimentos, saberes, fazeres que, manifestados no lugar, em seu cotidiano, vão se estabelecendo como parte de relações que se constituem nas territorialidades e no espaço vivido.

Esse cotidiano é evidenciado nas formas como organizam o trabalho, nas crenças e rezas, na educação e ensino, nas relações com os parentes e vizinhos, nas formas de lazer, nos modos como pensam e conversam sobre a política, a religião, o futebol, nos métodos utilizados para existirem, a despeito dos seus problemas e tensões, sobretudo os que envolvem os processos de reocupação do espaço. Para Bourdin (2001, p. 207), "a vida cotidiana é uma experiência geralmente organizada por um conjunto de regularidades, o modo de vida, também ligado a um quadro de vida, [...] dominado, pelo trabalho, pelo grupo de pertença, pela família [...]".

O modo de vida camponês está relacionado ao coletivo, havendo momentos de individualidade, mas com laços profundos no âmbito comunitário. Braga, Fiúza e Remoaldo (2017) apresentam dois momentos em que as práticas coletivas passam pela pesquisa e análise científica de um grupo social:

Por um lado, à análise da relação entre as diferentes práticas cotidianas, trabalho, vida familiar, consumo, lazer e etc. e, por outro lado, às relações que o conjunto dessas práticas cotidianas estabelece com as relações sociais mais gerais. Assim, os estudos ligados aos aspectos da vida cotidiana deveriam preocupar-se com o grau de consciência dos atores sobre a condução dos seus destinos, individuais ou coletivos. (BRAGA; FIÚZA; REMOALDO, 2017, p. 372). 
Portanto, a produção dos meios de vida busca na essência camponesa as explicações para a sua existência. Essa essência constitui-se nas experiências dos sujeitos com o espaço, com o lugar, com a escola e com seus territórios estabelecidos a partir de suas relações culturais de uma vida simples, com o resultado de seu trabalho e das relações sociais que os envolvem.

Segundo Kudlavicz e Almeida (2013), a II Conferência Nacional por uma Educação Básica do Campo, realizada em 2004, foi o marco fundamental para o processo de luta e pressão junto ao Estado para a implantação de uma educação diferenciada ao homem do campo, no qual foram estabelecidas algumas das diretrizes para a escola rural. Dentre elas Kudlavicz e Almeida (2013, p. 97), destacam que:

A escola é um dos espaços para antecipar, pela vivência e pela correção fraterna, as relações humanas que cultivem a cooperação, a solidariedade, o sentido de justiça, o zelo pela natureza [...]. A Educação do Campo deve prestar especial atenção às raízes da mulher e do homem do campo, que se expressam em culturas distintas, e perceber os processos de interação e transformação. [...] a Educação do Campo, a partir de práticas e estudos científicos, deve aprofundar uma pedagogia que respeite a cultura e a identidade dos povos do campo: tempos, ciclos da natureza, mística da terra, valorização do trabalho, festas populares [...].

Essas diretrizes foram fundamentais para a elaboração de propostas pedagógicas voltadas ao ensino para as escolas do campo. Nesse sentido, Souza (2010, p. 20) entende que "o termo educação no campo possibilita a reflexão e a construção da escola do campo, que valoriza a identidade camponesa, congregando a pluralidade das ideias e das concepções pedagógicas [...]". Desse modo, é necessário que a escola esteja não apenas no campo, mas que seja pensada a partir do campo.

Entretanto, é importante lembrar, segundo Almeida (2013), que a Educação do Campo surgiu como uma contraposição ao projeto do agronegócio, que visa ao esvaziamento do campo a partir da expulsão das famílias camponesas, e da lógica da não necessidade de escolas no campo, que recebe cada vez menos gente. Nesse sentido, afirma a autora, foi fundamental a inclusão de um artigo específico na Lei de Diretrizes e Bases da Educação Nacional - (LDB) n. 9394/96 -, que trata da educação para a população rural, conforme Almeida (2013, p. 97):

$\mathrm{Na}$ oferta de educação básica para a população rural, os sistemas de ensino promoverão as adaptações necessárias à sua adequação às peculiaridades da vida rural e de cada região, especialmente:

I - conteúdos curriculares e metodologias apropriadas às reais necessidades e interesses dos alunos da zona rural;

II - organização escolar própria, incluindo adequação do calendário escolar às fases do ciclo agrícola e às condições climáticas; 
III - adequação à natureza do trabalho na zona rural (BRASIL, 2005, p.16).

Um fato preocupante, de acordo com Souza (2010, p. 24-25), é o fortalecimento do "território imaterial do agronegócio sobre as escolas no campo". Para a autora, as escolas trabalham uma pedagogia que apresenta o campo como território apenas de produção capitalizada, contribuindo para o fortalecimento da lógica do capital, para o enfraquecimento da identidade camponesa e dos seus vínculos com seu território, visto como espaço de (re)produção de vida.

Almeida (2013, p. 102-103) reforça que o desafio para as escolas e movimentos sociais do campo é lutar e prol da efetivação das diretrizes operacionais para a educação básica nas escolas do campo e exigir que as políticas públicas Estaduais e Municipais de Educação incorporem essas Diretrizes, a fim de que a elas sejam destinados recursos via orçamento. De acordo com Jesus (2010b, p. 144). "as experiências com a Pedagogia da Alternância têm sido uma tentativa de efetivar um projeto de educação que possua uma proposta embasada na realidade do camponês".

[...] a metodologia da alternância desempenha um papel importante para o ensino no campo quando bem articulado e planejado pela equipe de monitores/professores, pois esta prática pedagógica propõe uma ação articulada com o meio social e profissional da realidade camponesa. Visualizou-se que o objetivo maior do projeto pedagógico da alternância é desenvolver questões geradoras que são difundidas pelas contradições do modelo capitalista no campo, as quais têm influências significativas no modo de vida dos campesinos (JESUS, 2010b, p. 134).

Segundo Jesus (2010b, p. 134), "essa prática pedagógica propõe uma ação articulada com o meio social e profissional da realidade camponesa", que se contrapõe ao modelo de formação ideológica do capital e revela as contradições e desigualdades sociais promotoras também do esvaziamento do campo e da reconcentração de terras, conforme discutido por Almeida (2013).

A Pedagogia da Alternância permite articular o ensino com o meio social e profissional da realidade camponesa, possibilitando que os educandos alternem alguns dias na escola com outros na propriedade, junto às suas famílias e à comunidade. A Alternância relaciona "a realidade vivida pelo jovem no meio familiar e o ensino" (JESUS, 2010b, p. 145):

Os valores familiares, a solidariedade, os mutirões, a ajuda mútua, a troca de dias de serviço, as festividades, os valores mais essenciais ao ser humano como o respeito ao próximo, a união, dignidade, honestidade, simplicidade e a partilha, sempre estiveram presentes na classe camponesa goiana (JESUS, 2010a, p. 162).

Pensar no cotidiano educacional é entender que o campo é um lugar de relações de vida, de trabalho, de cultura, socialmente construídos e que norteiam os estudos que 
nos chamam para a reflexão sobre o cotidiano (LOPES, 2010, p. 55) -pensando a Educação do campo pelo viés da interdisciplinaridade.

A vida no campo deve ser estudada pelas várias ciências e, portanto, ensinada nas escolas rurais por todas as disciplinas a partir da realidade do campo. A Matemática pode ajudar as crianças a entenderem os números, a fim de ajudar seus pais na contabilidade da produção e comercialização; no ensino de Língua Portuguesa, é preciso valorizar a variedade linguística local, para que a população rural não seja estereotipada pelo seu modo de falar; em Ciências, deve-se explorar a questão de que a produção camponesa promove pequenas alterações ao meio ambiente, incentivando a produção agroecológica de alimentos saudáveis; a Geografia e a História devem contribuir para a valorização histórica da luta pela terra como conquistas e reconquistas de um bem necessário à produção e à reprodução da vida.

Todas essas disciplinas precisam estabelecer a vida do campo como objeto de ensino, bem como estudar os sujeitos e suas experiências como conteúdo, com vistas a compreender as especificidades de cada uma delas. Não há negação da importância do livro didático, mas também é preciso ir além do que este material prevê, visando a um alcance didático e de conteúdo que esses livros não têm condições de apresentar (também não é aceitável que professores das escolas do campo continuem a utilizar livros didáticos elaborados para as escolas urbanas).

Para isso, é imprescindível também que os professores sejam sujeitos do campo, que convivam com a realidade dos alunos e das suas famílias, que sejam professores, mas também sujeitos dos conteúdos de ensino/aprendizagem repassados aos discentes e, de preferência, conteúdos construídos pelos próprios sujeitos da história: professores e alunos que estabelecem relações com a escola, com o trabalho, com a moradia e com o meio ambiente do campo.

\section{Considerações Finais}

Faz-se urgente a valorização e a defesa da proposta da Educação do Campo e suas pedagogias voltadas aos sujeitos do campo, a fim de conter o fluxo migratório para as cidades, imposto pelo planejamento estratégico do agronegócio. Faz-se necessário compreender que, para as sociedades locais, não é interessante a produção voltada para o mercado externo, pois as riquezas geradas não ficam na região. A pequena produção está voltada para as cadeias curtas de comercialização, gerando divisas para os municípios próximos do processo. Vale ressaltar que algumas práticas e valores humanos, importantes para as comunidades locais, têm sido destroçados pelo capital agrário.

Dentre as práticas pedagógicas trabalhadas nas EFAs de Goiás, estão presentes, dentre outras, os mutirões realizados pelos educandos, que têm como princípio fortalecer os valores de solidariedade como atividades que fazem parte do modo de vida dos camponeses. Assim, a realização de tais práticas na escola contribui para o fortalecimento da população campesina.

No entanto, é necessário implementar um ensino/aprendizagem interdisciplinar. As várias disciplinas precisam estar interconectadas com as experiências dos modos de 
vida e de produção rural local e seus respectivos conteúdos disciplinares. É preciso repensar as práticas de ensino, reformulando novas metodologias para as escolas do campo e estabelecendo novas perspectivas metodológicas e pedagógicas. Há que adaptar as propostas de escolas do campo em assentamentos para as comunidades rurais que não dispõem da experiência dos movimentos sociais e da luta pela terra.

Faz-se necessário pensar em estratégias para fortalecer as organizações sociais que lutam em defesa dos povos do campo, promover debates e reflexões nos espaços acadêmicos, com a participação dos movimentos sociais e professores para repensar as metodologias de ensino nas escolas rurais, atentar para a formação e qualificação dos profissionais que atuam nas escolas no campo. Um dos desafios de fazer um ensino contextualizado com a realidade sociocultural do homem do campo é, sem dúvidas, formar professores do campo.

Por isso, é preciso melhorar as políticas públicas já existentes e criar novas políticas públicas para o campo, que venham ao encontro dos interesses dos sujeitos que trabalham na terra: fomentando alternativas de geração de emprego e renda para garantir a permanência na terra. Dessa forma, o objetivo deve ser o de construir um projeto de educação no/do campo que atenda aos anseios das famílias camponesas.

Outros desafios também importantes são: melhorar a infraestrutura física das escolas rurais; construir biblioteca e laboratório de informática com internet e envolver os professores na construção do Projeto Político Pedagógico a partir da realidade do campo, já que muitas escolas ainda não o elaboraram. Iniciativas dessa natureza ajudariam a rediscutir as possibilidades de como fazer o ensino nas escolas rurais.

Logo, o campo precisa ser pensado a partir das suas particularidades e singularidades históricas e culturais, pois é em consonância com a sua diversidade de sujeitos que se deve construir um projeto pedagógico embasado numa concepção dialética e interdisciplinar para o ensino nas escolas rurais.

\section{Referências}

ALMEIDA, R. A. de. Educação do campo: fundamentos filosóficos, sociológicos, históricos, políticos e econômicos: módulo III. Campo Grande: Ed. UFMS, 2013. (Caderno de reflexão).

ARROYO, M. G; CALDART, R. S; MOLINA, M. C. (Org.). Por uma educação do campo, 2. ed. Petrópolis, RJ: Vozes, 2004.

BERTTI, M. S. Memória de Assentamentos Rurais como trabalho de Saber. In: PESSOA, J. M. de (Org.). Educação e ruralidades. Goiânia: Editora UFG, 2007.

BOURDIN, A. A questão local. Tradução de Orlando dos Santos Reis. Rio de Janeiro: DP\&A, 2001.

BRAGA, G. B.; FIÚZA, A. L. C; REMOALDO, P. C. A. O conceito de modo de vida: entre traduções, definições e discussões. Sociologias, Porto Alegre, ano 19, n. 45, p. 370- 
396, maio/ago. 2017. Disponível em:

$<$ http://seer.ufrgs.br/index.php/sociologias/article/view/65878/42672 >. Acesso em: 7 fev. 2018.

BRASIL. Lei de Diretrizes e Bases da Educação Nacional - (LDB) n. 9394/96. Brasília, 2005. Disponível em: $<$ https://www2.senado.leg.br/bdsf/bitstream/handle/id/70320/65.pdf $>$. Acesso em 7 fev. 2018.

CALDART, R. S. Elementos para construção do Projeto Político e Pedagógico da Educação do Campo. In: MOLINA, M. C; JESUS, S. M. S. A. de (Org.). Contribuições para a construção de um projeto de Educação do campo, n. 5, Brasília, DF: Articulação Nacional "Por Uma Educação do Campo", 2004.

CONFERÊNCIA NACIONAL POR UMA EDUCAÇÃO DO CAMPO. Luziânia/GO, 2 a 6 de agosto de 2004. Disponível em:

$<$ file:///C:/Users/Windows8/Downloads/declaracion-II-conferencia-educacaocampo\%20(1).pdf>. Acesso em: 7 fev. 2018.

COSTA, E. R. da; ALVES, M. Z.; FALEIRO, W. A interdisciplinaridade no Curso de Educação do Campo: o caso da UFG Catalão. Enciclopédia biosfera: Centro Científico Conhecer, Goiânia, v. 11, n. 20, p. 48-55, 2015.

FERNANDES, B. M.; MOLINA, M. C. O campo da educação do campo. In: MOLINA, M. C.; JESUS, S. M. A. de. (Org.). Contribuições para a construção de um projeto de educação do campo. Brasília, DF: Articulação Nacional "Por uma educação do campo", 2004.

JESUS, J. N. de. As escolas família agrícola no território goiano: a pedagogia da alternância como perspectiva para o desenvolvimento e o fortalecimento da agricultura camponesa. 2010. 242 f. Dissertação (Mestrado em Geografia) - Universidade Federal de Goiás, Goiânia, 2010a.

JESUS, J. N. de. Escolas Família Agrícola: perspectivas e desafios na construção de um projeto de educação do campo em Goiás. In: SOUZA, Francilane Eulália (Org.). Geografia e educação do campo: para que e para quem serve a educação no campo do Estado de Goiás? Goiânia: Ed. Vieira, 2010b, p. 133-156.

KOLling, E. J; NERY, I. J; MOLINA, M. C. Por uma educação básica do campo. Brasília: Ed. Universidade de Brasília, 1999.

KUDLAVICZ, M; ALMEIDA, R A. Abrindo caminhos para uma educação que valoriza os saberes do homem e da mulher do campo. In: ALMEIDA, Rosemeire Aparecida de. Educação do campo: fundamentos filosóficos, sociológicos, históricos, políticos e econômicos: módulo III. Campo Grande: Ed. UFMS, 2013, p. 95-99. (Caderno de reflexão).

LEITE, S. C. Escola rural: urbanização e políticas educacionais, 2. ed. São Paulo, Cortez, 2002. (Coleção Questões da Época, v. 70). 
LOPES, M. P. A relevância do cotidiano do aluno na construção do saber. In. SOUZA, F. E. (Org.). Geografia e educação do campo: para que e para quem serve a educação no campo do Estado de Goiás? Goiânia: Ed. Vieira, 2010, p. 33-56.

PERES, M. A. de C. Velhice e analfabetismo, uma relação paradoxal: a exclusão educacional em contextos rurais da região Nordeste. Revista sociedade e estado, v. 26, n. 3. p. 631-661, set/dez, 2011. Disponível em:

$<$ http://www.scielo.br/pdf/se/v26n3/11.pdf>. Acesso em: 7 fev. 2018.

PESSOA, J. M. de (Org.). Educação e ruralidades. Goiânia: Editora UFG, 2007.

PIRES, A. M. Educação do campo como direito humano, v. 4, São Paulo: Cortez, 2012. (Coleção Educação em Direitos Humanos).

SANTOS, A. V. dos; ALMEIDA, L. S. C. de. Perspectivas curriculares para a educação do campo: algumas aproximações para construção do currículo da escola dos que vivem no e do campo. In: GHEDIN, E. (Org). Educação do campo: epistemologia e práticas. São Paulo: Cortez, 2012, Cap. V, p. 137-156.

SOUZA, F. E. O papel das escolas do campo para o fortalecimento do campesinato na disputa territorial no Estado de Goiás. In: SOUZA, F. E. (Org). Geografia e educação do campo: para que e para quem serve a educação no campo do Estado de Goiás? Goiânia: Ed. Vieira, 2010, p.11-32.

José Novais de Jesus

Doutorando em Geografia pela Universidade Federal de Goiás, onde também cursou seu mestrado. Possui licenciatura em Geografia pela Universidade Estadual de Goiás Câmpus da Cidade de Goiás. É professor do curso de Geografia da Universidade Estadual de Goiás, no Câmpus de Quirinópolis.

Av. Garibalde Teixeira, 300, Hélio Leão. Cep: 75860-000, Quirinópolis-GO

E-mail: novaisdejesus@yahoo.com.br

\section{Edevaldo Aparecido Souza}

Doutor em Geografia pela Universidade Federal de Uberlândia. Mestre em Geografia pela Universidade Estadual Paulista Júlio de Mesquita Filho - Unesp de Presidente Prudente. Graduado em Geografia pela UFMS, Campus de Três Lagoas. Atualmente está em estágio Pós-Doutoral na Universidade Federal de Mato Grosso do Sul, Câmpus Três Lagoas. É professor titular da Universidade Estadual de Goiás, no Câmpus Quirinópolis. Rua José Martins sobrinho, 03, Alexandrina. Cep: 75860-000, Quirinópolis-GO.

E-mail: ediueg@gmail.com 